Neurosurg Focus 18 (3):E8, 2005

\title{
Combination kyphoplasty and spinal radiosurgery: a new treatment paradigm for pathological fractures
}

\author{
Peter C. Gerszten, M.D., M.P.H., Anand Germanwala, M.D., Steven A. Burton, M.D., \\ William C. Welch, M.D., Cihat Ozhasoglu, Ph.D., and William J. Vogel, R.T.(T)
}

Departments of Neurological Surgery and Radiation Oncology, University of Pittsburgh Medical Center, Pittsburgh, Pennsylvania

\begin{abstract}
Object. Patients with symptomatic pathological compression fractures require a stabilization procedure for mechanical control of back pain as well as radiation therapy for the underlying malignant process. In this study the authors evaluated a treatment paradigm of closed fracture reduction and fixation in which kyphoplasty was used, followed by single-fraction spinal radiosurgery performed with the CyberKnife.

Methods. Twenty-six patients (six men and 20 women, mean age 72 years) with histologically confirmed pathological compression fractures (16 thoracic, 10 lumbar) were prospectively evaluated. For inclusion in the study, the patients' presenting symptoms were limited to pain without neurological deficits. Histological findings included 11 lung, nine breast, and four renal carcinomas, one cholangiocarcinoma, and one ocular melanoma. All patients underwent kyphoplasty of the affected vertebral body, for which a percutaneous transpedicular procedure was used. Fiducial markers that allow image guidance for CyberKnife radiosurgery were placed into the pedicles at the adjacent levels at the time of the kyphoplasty procedure. Patients then underwent single-fraction radiosurgery (at a mean of 12 days after kyphoplasty) in an outpatient setting. The tumor dose was maintained at 16 to 20 Gy to the $80 \%$ isodose line (mean $18 \mathrm{~Gy})$. Treated tumor volume ranged from 12.7 to $37.1 \mathrm{~cm}^{3}$. Axial pain improved in $24(92 \%)$ of 26 patients during the follow-up period of 7 to 20 months.

Conclusions. A combined kyphoplasty and spinal radiosurgery treatment paradigm was found to be safe and clinically effective for patients with pathological fractures without significant spinal canal compromise. This technique combines two minimally invasive surgical procedures, thereby avoiding the morbidity associated with open surgery while providing immediate fracture fixation as well as a single-fraction tumoricidal radiation dose.
\end{abstract}

\section{KEY WORDS - vertebral compression fracture - spinal metastases • image-guided surgery $\bullet$ kyphoplasty $・$ robotic surgery $\bullet$ stereotactic radiosurgery}

Metastatic spinal tumors affect a large number of patients each year, resulting in significant pain, destruction of the spinal column causing mechanical instability, and neurological deficits. ${ }^{8,54,55}$ It is estimated that in the US more than 20,000 cancer patients per year experience spinal cord or nerve root compression as a manifestation of metastatic disease. In approximately $30 \%$ of patients with cancer, symptomatic spinal metastases may develop during the course of the illness, and pain is the presenting symptom in most cases. ${ }^{13,21,52,53}$ The goal of the treatment of metastatic lesions involves stabilization of the spine as well as treatment of the tumor within the VB. Patients with painful pathological compression fractures require a stabilization procedure for mechanical pain control as well as radiation therapy for tumor control.

The percutaneous injection of acrylic materials into a fractured VB, called vertebroplasty, was developed in France and was first described in $1987 .{ }^{23}$ For this proce-

Abbreviations used in this paper: $\mathrm{CT}=$ computerized tomography; $\mathrm{MMA}=$ methyl methacrylate $; \mathrm{MR}=$ magnetic resonance; $\mathrm{VB}=$ vertebral body. dure the surgeon uses a large-bore needle to access a fractured VB percutaneously, inject bone cement, and thereby stabilize and reinforce the remaining bone structure. The procedure was first used to treat vertebral hemangiomas and was later applied to both osteolytic metastases and osteoporotic compression fractures. ${ }^{2,4,15,18,39,51}$ Although this method is used to treat both osteoporotic and pathological compression fractures, the majority of experience in the US so far has been with osteoporotic bone disease. Multiple observational cohort studies have been published in which the safety and efficacy of vertebroplasty has been documented. 4,14,18,32,42,53 The primary outcomes measure for these studies has been pain reduction; in most series a greater than $90 \%$ success rate has been reported based on this outcomes measure.

The percutaneous balloon kyphoplasty procedure differs from vertebroplasty in that it attempts to address the limitation of little or no restoration of VB height with stabilization. This procedure involves the insertion of a balloon within the collapsed VB in an attempt to restore height and reduce kyphotic deformity prior to stabilization with polymethyl methacrylate..$^{19,22,24,35,36,50,53}$ The inflatable 
KyphX balloon (Kyphon, Inc., Sunnyvale, CA) is inserted through a cannula into the VB and inflated with a balloon-plasty technique, not only to create a focal cavity to fill with cement, but also to attempt reexpansion of the VB and thus regain height. ${ }^{29}$ Multiple studies conducted using validated outcomes instruments support the use of kyphoplasty as both safe and effective. . $^{1,6,16,19,29,31,34-36,43,44}$ Kyphoplasty has become a safe and highly effective method for the treatment of osteolytic vertebral compression fractures that is associated with early clinical improvement of pain and function as well as some restoration of VB height. ${ }^{19}$

There has been a rapid increase in the use of radiosurgery as a treatment alternative for malignant tumors involving the spine. ., $, 17,27,46$ Recent technological developments, including imaging advancements for threedimensional localization and pretreatment planning, the advent of intensity-modulated radiation therapy, and a higher degree of accuracy in achieving target dose conformation while sparing normal surrounding tissue have allowed clinicians to expand radiosurgery applications to treat malignant VB lesions close to the spinal cord and cauda equina. Radiosurgery delivers a large, single, highly conformal radiation dose to a localized tumor via a stereotactic approach. ${ }^{54}$ This modality has been shown to be very effective for controlling intracranial malignancies. $3,11,20,33,37,38,49$ Stereotactic radiosurgery for tumors of the spine has been demonstrated more recently to be accurate, safe, and efficacious. $5,7,10,17,27,30,40,41,45-47,54$

In patients with pain caused by pathological compression fractures associated with minimal spinal canal compromise, combining a kyphoplasty fracture fixation procedure followed by spinal radiosurgery would allow for the immediate stabilization of the fracture as well as for the delivery of a tumoricidal dose to control local disease progression. Both procedures are intended to help relieve the underlying pain associated with this condition, thereby improving the patient's quality of life. Our objective in this study was to assess the safety and efficacy of a combined kyphoplasty and spinal radiosurgery procedure for the treatment of painful VB compression fractures in patients with cancer.

\section{CLINICAL MATERIAL AND METHODS}

\section{Study Protocol}

This study was a prospective evaluation of 26 consecutive patients in whom pain caused by pathological compression fractures from metastatic disease was treated with closed fracture reduction by using the KyphX balloon (Kyphon, Inc., Sunnyvale, CA) to perform the kyphoplasty technique. This treatment was followed by spinal radiosurgery delivered by the CyberKnife ImageGuided Radiosurgery System with the aid of Dynamic Tracking System 3.0 software (Accuray, Inc., Sunnyvale, CA). All patients were treated at the University of Pittsburgh Medical Center in Pittsburgh, Pennsylvania, and the protocol was approved by the University of Pittsburgh's institutional review board. The study was designed to test the hypothesis that kyphoplasty followed by spinal radiosurgery is safe, feasible, and clinically effective for the treatment of pathological compression fractures.

\section{Patient Population}

The study cohort included 20 women and six men whose ages ranged from 47 to 83 years (mean 72 years). The primary cancer diagnoses included 11 lung, nine breast, and four renal carcinomas, one ocular melanoma, and one cholangiocarcinoma. Sixteen lesions were in the thoracic and 10 were in the lumbar spine. Seven lesions had previously undergone external-beam radiation treatment, with spinal cord tolerance doses that precluded any further conventional radiation therapy. Primary disease had been identified in all patients prior to the procedure. Therefore, the spinal radiosurgery was planned before the kyphoplasty procedure in all cases. Patients gave consent for the kyphoplasty procedure as well as for implantation of fiducial markers that would allow for subsequent image guidance during the radiosurgery procedure. Kyphoplasty was performed in all cases after induction of general anesthesia, as described elsewhere. ${ }^{19,21,29,35,53}$ There were no complications associated with the kyphoplasty procedure. After the kyphoplasty portion of the operation was completed, four to five $0.62 \times 5-\mathrm{mm}$ gold fiducial markers (Alpha/Omega Services, Bellflower, CA) were implanted into the adjacent pedicles both rostral and caudal to the lesion by using the same bilateral stab incisions. This technique is described elsewhere..$^{25}$

All patients subsequently underwent a treatment planning CT scan. The patients were placed supine in a conformal alpha cradle (Smither Products Inc., North Canton, $\mathrm{OH}$ ) during $\mathrm{CT}$ scanning as well as during treatment. The CT scans were acquired using 1.25 -mm-thick slices to include the lesion of interest as well as all fiducial markers. ${ }^{28}$ The entire VB and any adjacent tumor extension were included within the radiosurgical treatment plan as the target volume. The patients then underwent radiosurgical treatment of the lesion. All treatments were performed using a single-fraction procedure in an outpatient setting.

\section{RESULTS}

The two procedures were successfully completed in all patients. The mean time interval between the kyphoplasty and radiosurgery procedures was 12 days. The tumor dose was maintained at 16 to 20 Gy to the $80 \%$ isodose line contoured at the edge of the target volume. The maximum intratumoral dose ranged from 20 to $25 \mathrm{~Gy}$. The tumor volume ranged from 12.7 to $37.1 \mathrm{~cm}^{3}$ (mean $28.3 \mathrm{~cm}^{3}$ ). Follow-up duration for this patient cohort ranged from 7 to 20 months. For evaluation of pain relief, a 10-point verbal visual analog scale with intensity description was administered prior to kyphoplasty, at 1 month after radiosurgery, and at the last follow-up visit. Improvement in back pain occurred in 24 (92\%) of 26 patients (Fig. 1). During a maximum follow-up period of 20 months, there were no clinically detectable neurological signs that could be attributable to acute or subacute radiation-induced spinal cord damage. Postoperative MR imaging revealed no changes indicative of radiation-induced spinal cord injury. The barium-impregnated MMA injected at the level of the treated tumor did not interfere with tracking of the fiducial markers during the radiosurgery treatment.

Sixteen of the 26 patients were found to have some 


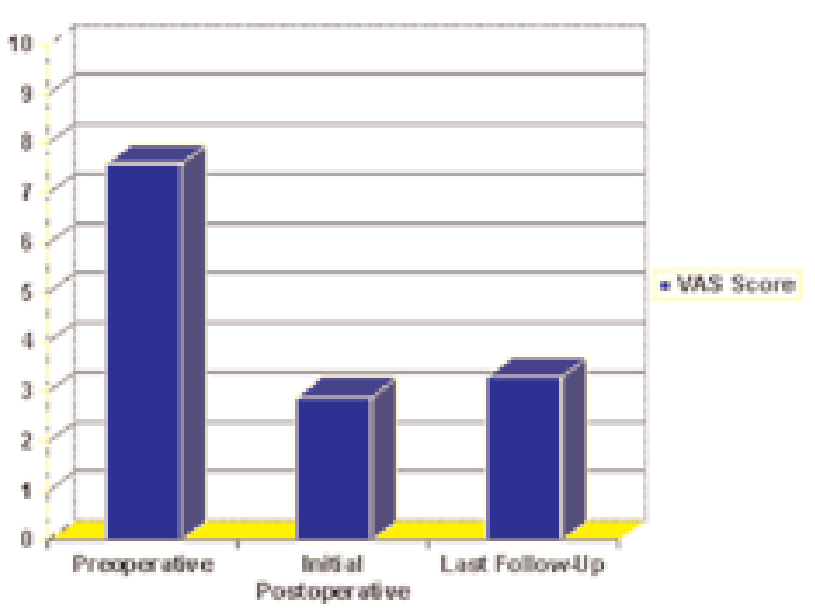

Fig. 1. Bar graph demonstrating the mean 10-point visual analog scale (VAS) pain scores in 26 patients at three time points: prior to kyphoplasty, at 1 month after radiosurgery, and at the last follow-up visit.

degree of correction of their kyphotic deformity based on plain $\mathrm{x}$-ray films and the $\mathrm{CT}$ simulation reconstruction after the treatment. There were two patients in whom no documented pain improvement occurred. In one of the treatment failures, a 71-year-old woman with a T-12 metastasis from an ocular melanoma continued to suffer progressive kyphosis, for which she ultimately required a posterior decompressive laminectomy for progressive spinal cord compression. (The tumor had been treated with a 20-Gy dose.) In the second treatment failure, the patient was a 62-year-old woman who had a metastatic cholangiocarcinoma of the L-2 VB. Soon after treatment, the patient suffered a significant pathological fracture of her left hip. The complexity of the hip fracture precluded orthopedic surgical intervention. It was not possible for her to state whether she attained any significant relief after the kyphoplasty and radiosurgery because of poor pain control from her other fracture. Her treatment was considered to have failed.

\section{ILLUSTRATIVE CASE}

This 57-year-old woman with metastatic renal cell carcinoma (Fig. 2) reported severe axial pain through the midthoracic spine. An MR image revealed destruction of the T-6 VB with a compression fracture associated with kyphosis but without significant spinal canal compromise. She underwent a T-6 kyphoplasty procedure with a $5-\mathrm{cm}^{3}$ injection of MMA. The patient noted significant pain relief immediately after the kyphoplasty procedure. On postoperative Day 1 she underwent a planning CT scan for the CyberKnife treatment. On postoperative Day 7 she underwent focused stereotactic radiosurgery, by which the tumor was treated with $22.5 \mathrm{~Gy}$ in a single fraction (18 Gy at the $80 \%$ isodose line). The lesion volume was $17.9 \mathrm{~cm}^{3}$. The maximum dose to the spinal cord was $9 \mathrm{~Gy}$, and 0.02 $\mathrm{cm}^{3}$ of the spinal cord received more than $8 \mathrm{~Gy}$. The patient had never undergone external-beam radiation therapy for this lesion.

\section{DISCUSSION}

The current nonsurgical treatment options for malignant spinal disease include analgesic medication, radiation therapy, hormone therapy, cytotoxic drugs, embolization, and bisphosphonates ${ }^{48}$ Open surgical intervention is usually reserved for patients in whom nonsurgical treatment has failed. Open surgery can be associated with significant morbidity and limited local tumor control. Conversely, radiation therapy may provide less than optimal pain relief and tumor control because the total dose is limited by the tolerance of adjacent tissues, namely the spinal cord. It often happens that pathological compression of the VB progresses after external-beam radiation therapy. Further radiation treatment will not improve the patient's pain related to mechanical instability. In recent series investigators have demonstrated a significant improvement in pain associated with cancer-related compression fractures by using percutaneous injection of MMA in VBs, using either the vertebroplasty ${ }^{15,21,51}$ or kyphoplasty ${ }^{19,21}$ procedure.

Injection of MMA into the involved VB allows for immediate stabilization of the fracture. Nevertheless, there remains the issue of treatment of the underlying tumor cells within the affected VB. The presence of these cells inhibits normal bone regrowth and subsequent fracture healing. The emerging technique of spinal radiosurgery represents a logical extension of the current state of the art in radiation therapy. $5,7,10,17,27,30,40,41,45-47,54$ It has the potential to improve local control of spinal tumors significantly. Spinal radiosurgery might also offer improved pain control and a longer duration of pain control by delivering larger radiobiological doses. Furthermore, this technique allows for the treatment of lesions that have been previously irradiated using external-beam radiation therapy. Another advantage to the patient is that radiation therapy can be completed in a single day rather than over the course of several weeks. ${ }^{27}$

In this series, a combined kyphoplasty and spinal radiosurgery treatment paradigm was found to be feasible, safe, and clinically effective in patients with pathological fractures. This combination of two minimally invasive surgical procedures avoids the morbidity associated with open surgical therapy while allowing for a single-fraction tumoricidal radiation dose. Pathological fractures with significant spinal cord compromise would require open surgery and would preclude the kyphoplasty procedure. Nevertheless, at the time of open surgery, fiducial markers may be still be implanted so that a radiosurgical treatment can be delivered to the affected VB in the postoperative period.

Performing this procedure earlier in the course of the patient's disease, before there is significant VB collapse, might prevent further collapse and subsequent spinal canal compromise that would necessitate a larger open surgical intervention. Such surgeries often require instrumentation to be implanted to accomplish spinal stabilization. Open surgeries for spinal metastases are associated with significant morbidity and a high complication rate in these already debilitated patients..$^{21,26}$ Furthermore, open surgery necessitates a postoperative recovery period that is not inconsequential for a patient with an already limited life expectancy. 


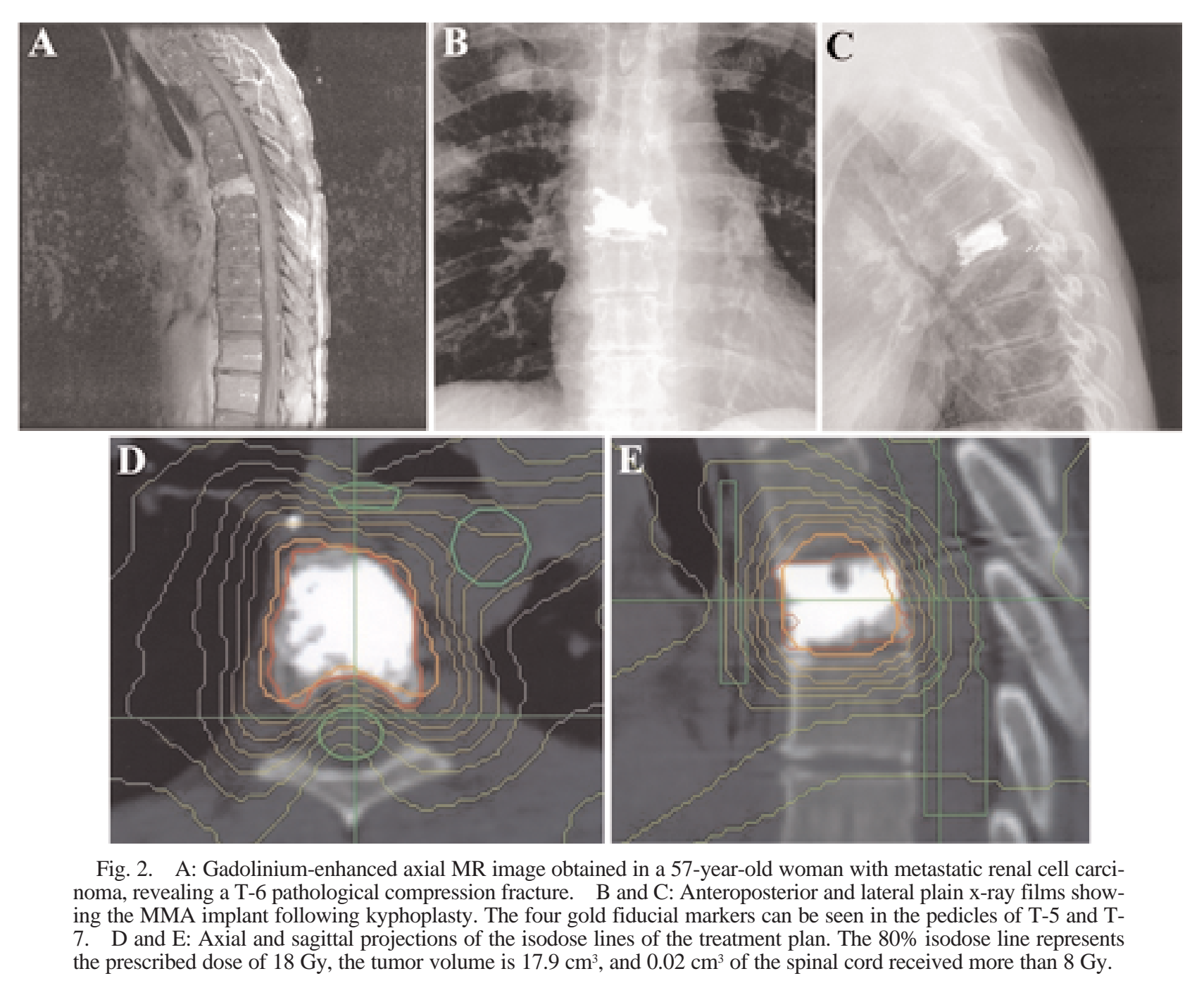

In spinal radiosurgery, the spinal cord is relatively spared from irradiation, while the tumor receives a higher dose than is possible with conventional radiation therapy. ${ }^{17}$ This approach avoids the need to irradiate large segments of the spinal cord as well as the bone marrow within adjacent VBs. It may also avoid the need to irradiate large segments of the spinal column, a procedure that is known to have a deleterious effect on bone marrow reserves in these patients. This would facilitate continuous chemotherapy for this vulnerable patient population. Ryu, et al. ${ }^{46}$ found a relatively rare occurrence of failure at the treated as well as at adjacent spinal segments, thereby lending support for radiosurgery targeting only to the involved single spinal segment. These authors also found that progressive pathological fracture of the treated VB was a major cause of treatment failure after radiosurgery. The placement of MMA within the VB prior to radiosurgery might very well prevent this pattern of failure.

The optimal treatment doses for spinal radiosurgery

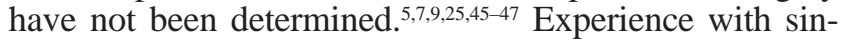
gle-fraction radiation therapy of brain metastases has shown that lesions typically resistant to conventional fractionation regimens can be controlled and even obliterated when applying a large single dose of radiation. ${ }^{12,17}$ Similar to their effect in the brain, doses greater than 18 Gy may be required to achieve long-term control of metastatic spinal lesions. Our experience with more than 400 singlefraction spinal radiosurgery cases has yielded encouraging results in relation to long-term control when maximum doses of 20 to $25 \mathrm{~Gy}$ are used.

\section{CONCLUSIONS}

In this study we have demonstrated that closed fracture reduction and fixation with MMA by using the kyphoplasty technique, followed by single-fraction CyberKnife radiosurgery, was a safe, feasible, and clinically effective treatment modality for patients with pain caused by pathological compression fractures. Our goal in using this technique is to provide good palliative effects at the specific location of disease that is causing pain and associated disability. Despite systemic therapy and even adequate local tumor control, in these patients with metastatic cancer the disease often progresses and becomes symptomatic at areas both within and outside of the spine, as seen in the two treatment failures in our series. This new paradigm plays an important role in the minimally invasive treatment of patients with symptomatic spinal metastases. 
Kyphoplasty and radiosurgery for pathological fractures

\section{References}

1. Ahmad Z, Abbasi F, Mitsunaga M, et al: Pain reduction and functional improvement after kyphoplasty: a retrospective study of 50 patients. Arch Phys Med Rehabil 84:A21, 2003 (Abstract)

2. Amar AP, Larsen DW, Esnaashari N, et al: Percutaneous transpedicular polymethylmethacrylate vertebroplasty for the treatment of spinal compression fractures. Neurosurgery 49: 1105-1115, 2001

3. Auchter RM, Lamond JP, Alexander E, et al: A multiinstitutional outcome and prognostic factor analysis of radiosurgery for resectable single brain metastasis. Int J Radiat Oncol Biol Phys 35:27-35, 1996

4. Barr JD, Barr MS, Lemley TJ, et al: Percutaneous vertebroplasty for pain relief and spinal stabilization. Spine 25:923-928, 2000

5. Benzil DL, Saboori M, Mogilner AY, et al: Safety and efficacy of stereotactic radiosurgery for tumors of the spine. J Neurosurg 101 (Suppl 3):413-418, 2004

6. Berlemann U, Franz T, Orler R, et al: Kyphoplasty for treatment of osteoporotic vertebral fractures: a prospective non-randomized study. Eur Spine J 13:496-501, 2004

7. Bilsky MH, Yamada Y, Yenice K, et al: Intensity-modulated stereotactic radiotherapy of paraspinal tumors: a preliminary report. Neurosurgery 54:823-831, 2004

8. Black P: Spinal metastases: current status and recommended guidelines for management. Neurosurgery 5:726-746, 1979

9. Chang EL, Shiu AS, Lii MF, et al: Phase I clinical evaluation of near-simultaneous computed tomographic image-guided stereotactic body radiotherapy for spinal metastases. Int J Radiat Oncol Biol Phys 59:1288-1294, 2004

10. Chang SD, Adler JR Jr: Current status and optimal use of radiosurgery. Oncology 15:209-221, 2001

11. Chang SD, Adler JR Jr, Hancock SL: Clinical uses of radiosurgery. Oncology 12:1181-1192, 1998

12. Chitapanarux I, Goss B, Vongtama R, et al: Prospective study of stereotactic radiosurgery without whole brain radiotherapy in patients with four or less brain metastases: incidence of intracranial progression and salvage radiotherapy. J Neurooncol 61:143-149, 2003

13. Cobb CA III, Leavens ME, Eckles N: Indications for nonoperative treatment of spinal cord compression due to breast cancer. J Neurosurg 47:653-658, 1977

14. Cortet B, Cotten A, Boutry N, et al: Percutaneous vertebroplasty in the treatment of osteoporotic vertebral compression fractures: an open prospective study. J Rheumatol 26:2222-2228, 1999

15. Cotten A, Boutry N, Cortet B, et al: Percutaneous vertebroplasty: state of the art. Radiographics 18:311-323, 1998

16. Coumans JV, Reinhardt MK, Lieberman IH: Kyphoplasty for vertebral compression fractures: 1-year clinical outcomes from a prospective study. J Neurosurg Spine 99:44-50, 2003

17. De Salles AA, Pedroso AG, Medin P, et al: Spinal lesions treated with Novalis shaped beam intensity-modulated radiosurgery and stereoactic radiotherapy. J Neurosurg 101 (Suppl 3): 435-440, 2004

18. Deramond H, Depriester C, Galibert P, et al: Percutaneous vertebroplasty with polymethylmethacrylate. Technique, indications and results. Radiol Clin North Am 36:533-546, 1998

19. Dudeney S, Lieberman IH, Reinhardt MK, et al: Kyphoplasty in the treatment of osteolytic vertebral compression fractures as a result of multiple myeloma. J Clin Oncol 20:2382-2387, 2002

20. Flickinger JC, Kondziolka D, Lunsford LD, et al: A multi-institutional experience with stereotactic radiosurgery for solitary brain metastasis. Int J Radiat Oncol Biol Phys 28:797-802, 1994

21. Fourney DR, Schomer DF, Nader R, et al: Percuteanous vertebroplasty and kyphoplasty for painful vertebral body fractures in cancer patients. J Neurosurg Spine 98:21-30, 2003
22. Fribourg D, Tang C, Sra P, et al: Incidence of subsequent vertebral fracture after kyphoplasty. Spine 29:2270-2277, 2004

23. Galibert P, Deramond H, Rosat P, et al: Note preliminaire sur le traitement des angiomes vertebraux par vertebroplastie acrylique percutanee. Neurochirurgie 33:166-168, 1987

24. Garfin SR, Yuan HA, Reiley MA: New technologies in spine: kyphoplasty and vertebroplasty for the treatment of painful osteoporotic compression fractures. Spine 26:1511-1515, 2001

25. Gerszten PC, Ozhasoglu C, Burton S, et al: CyberKnfe frameless stereotactic radiosurgery for spinal lesions: clinical experience in 125 cases. Neurosurgery 55:89-99, 2004

26. Gerszten PC, Welch WC: Current surgical management of metastatic spinal disease. Oncology 14:1013-1030, 2000

27. Gerszten PC, Welch WC: Cyberknife radiosurgery for metastatic spine tumors. Neurosurg Clin N Am 15:491-501, 2004

28. Gerszten PC, Welch WC: CyberKnife radiosurgery for the spine. Techn Neurosurg 9:232-241, 2003

29. Halpin RJ, Bendok BR, Liu JC: Minimally invasive treatments for spinal metastases: vertebroplasty, kyphoplasty, and radiofrequency ablation. J Support Oncol 2:339-355, 2004

30. Hamilton AJ, Lulu BA, Fosmire H, et al: Preliminary clinical experience with linear accelerator-based spinal stereotactic radiosurgery. Neurosurgery 36:311-319, 1995

31. Hardouin P, Fayada P, Leclet H, et al: Kyphoplasty. Joint Bone Spine 69:256-261, 2002

32. Jensen ME, Evans AJ, Mathis JM, et al: Percutaneous polymethylmethacrylate vertebroplasty in the treatment of osteoporotic vertebral body compression fractures: technical aspects. AJNR 18:1897-1904, 1997

33. Kondziolka D, Patel A, Lunsford LD, et al: Stereotactic radiosurgery plus whole brain radiotherapy versus radiotherapy alone for patients with multiple brain metastases. Int J Radiat Oncol Biol Phys 45:427-434, 1999

34. Lane JM, Johnson CE, Khan SN, et al: Minimally invasive options for the treatment of osteoporotic vertebral compression fractures. Orthop Clin North Am 33:431-438, viii, 2002

35. Ledlie JT, Renfro M: Balloon kyphoplasty: one-year outcomes in vertebral body height restoration, chronic pain, and activity levels. J Neurosurg Spine 98:36-42, 2003

36. Lieberman IH, Dudeney S, Reinhardt MK, et al: Initial outcome and efficacy of "kyphoplasty" in the treatment of painful osteoporotic vertebral compression fractures. Spine 26:1631-1638, 2001

37. Loeffler JS, Alexander E III: Radiosurgery for the treatment of intracranial metastasis, in Alexander E III, Loeffler JS, Lunsford LD (eds): Stereotactic Radiosurgery. New York: McGraw-Hill, 1993, pp 197-206

38. Loeffler JS, Kooy HM, Wen PY, et al: The treatment of recurrent brain metastases with stereotactic radiosurgery. J Clin Oncol 8:576-582, 1990

39. Martin J, Jean B, Sugiu K, et al: Vertebroplasty: clinical experience and follow-up results. Bone 25 (Suppl 2):11S-15S, 1999

40. Medin PM, Solberg TD, De Salles AA, et al: Investigations of a minimally invasive method for treatment of spinal malignancies with LINAC stereotactic radiation therapy: accuracy and animal studies. Int J Radiat Oncol Biol Phys 52:1111-1122, 2002

41. Milker-Zabel S, Zabel A, Thilmann C, et al: Clinical results of retreatment of vertebral bone metastases by stereotactic conformal radiotherapy and intensity-modulated radiotherapy. Int $\mathbf{J}$ Radiat Oncol Biol Phys 55:162-167, 2003

42. Peters KR, Guiot BH, Martin PA, et al: Vertebroplasty for osteoporotic compression fractures: current practice and evolving techniques. Neurosurgery 51 (Suppl 5):S96-S103, 2002

43. Phillips TL, Buschke F: Radiation tolerance of the thoracic spinal cord. Am J Roentengenol Radium Ther Nucl Med 105: 659-664, 1969

44. Rhyne A III, Banit D, Laxer E, et al: Kyphoplaty: report of 
eighty-two thoracolumbar osteoporotic vertebral fractures. J Orthop Trauma 18:294-299, 2004

45. Ryu S, Fang Yin F, Rock J, et al: Image-guided and intensitymodulated radiosurgery for patients with spinal metastasis. Cancer 97:2013-2018, 2003

46. Ryu S, Rock J, Rosenblum M, et al: Patterns of failure after single-dose radiosurgery for spinal metastasis. J Neurosurg 101 (Suppl 3):402-405, 2004

47. Ryu SI, Chang SD, Kim DH, et al: Image-guided hypo-fractionated stereotactic radiosurgery to spinal lesions. Neurosurgery 49:838-846, 2001

48. Schachar NS: An update on the nonoperative treatment of patients with metastatic bone disease. Clin Orthop 382:75-81, 2001

49. Sperduto PW, Scott C, Andrews D, et al: Stereotactic radiosurgery with whole brain radiation therapy improves survival in patients with brian metastases: report of Radiation Therapy Oncology Group Phase III study 95-08. Int J Radiat Oncol Biol Phys 54 (Suppl 1):3, 2002 (Abstract)

50. Theodorou D, Theodorou SJ, Duncan TD, et al: Percutaneous balloon kyphoplasty for the correction of spinal deformity in painful vertebral body compression fractures. Clin Imaging 26: $1-5,2002$
51. Weill A, Chiras J, Simon JM, et al: Spinal metastases: indications for and results of percutaneous injectin of acrylic surgical cement. Radiology 199:241-247, 1996

52. Wong DA, Fornasier VL, MacNab I: Spinal metastases: the obvious, the occult, and the impostors. Spine 15:1-4, 1990

53. Wong W, Reiley MA, Garfin S: Vertebroplasty/kyphoplasty. J Women's Imaging 2:117-124, 2000

54. Yin FF, Ryu S, Ajlouni M, et al: Image-guided procedures for intensity-modulated spinal radiosurgery. Technical note. J Neurosurg 101 (Suppl 3):419-424, 2004

55. Young JM, Funk FJ Jr: Incidence of tumor metastasis to the lumbar spine. A comparative study of roentgenographic changes and gross lesions. J Bone Joint Surg Am 35:55-64, 1953

Manuscript received January 11, 2005.

Accepted in final form February 7, 2005.

Address reprint requests to: Peter C. Gerszten, M.D., M.P.H., Department of Neurological Surgery, Presbyterian University Hospital, Suite B-400, 200 Lothrop Street, Pittsburgh, Pennsylvania 15213. email: gersztenpc@upmc.edu. 